See discussions, stats, and author profiles for this publication at: https://www.researchgate.net/publication/323493612

\title{
Evolutionary analysis of sustainable tourism
}

Article in Annals of Tourism Research · March 2018

DOI: 10.1016/j.annals.2018.02.002

3 authors, including:

Feifei Xu

Southeast University (China)

25 PUBLICATIONS 265 CITATIONS

SEE PROFILE

Some of the authors of this publication are also working on these related projects:

Project Call for book chapters "Gamification for Tourism" View project 


\title{
Evolutionary Analysis of Sustainable Tourism
}

\author{
Peng $\mathrm{He}^{1}$, Yong $\mathrm{He}^{*}, 1$ and Feifei $\mathrm{Xu}^{2}$ \\ ${ }^{1}$ School of Economics and Management, Southeast University, Nanjing 210096 \\ ${ }^{2}$ School of Humanities, Southeast University, Nanjing 210096 \\ *Corresponding author: Yong He, E-mail address: hy@ seu.edu.cn
}

\begin{abstract}
This paper aims to explore an effective green incentive mechanism for government to develop traditional tourism into green tourism by establishing a dynamic evolutionary game model among governments, tourism enterprises, and tourists. We first discuss the evolutionary stable strategy (ESS) regarding green innovation and its corresponding conditions for each stakeholder, and then analyze the ESS between tourism enterprises and tourists, with and without consideration of government green supervision. The optimal green incentive condition for driving all stakeholders to conduct green behavior is identified. More importantly, we advise the government to first implement green incentive mechanism in the areas where the tourism market scale is relatively small. Additionally, we utilize numerical examples to illustrate the findings and provide some managerial insights.
\end{abstract}

Keywords: Sustainable tourism; Green preference; Green innovation; Government incentive mechanism; Evolutionary game theory

\section{Introduction}

In recent decades, protecting the environment, improving the utilization rate of natural resources, and achieving the sustainable development of humans and nature have attracted enormous attention among people throughout the world (Buckley, 2012). China is no exception to this trend. China's economic development, over the last decades, has accelerated and also produced a negative impact on the ecological environment (Simões, 2016). From the report released by Asian Development Bank, less than $1 \%$ of the 500 largest Chinese cities meet the air quality standards suggested by the World Health Organization, and 7 of its cities are in the list of the 10 most polluted cities in the world (Zhang \& Crooks, 2012). As an important part of China's 
tertiary sector, the tourism industry, which witnessed a rapid growth in 2010 with 935 million international and 2103 million domestic tourist arrivals (Yan, 2013), has been growing rapidly. Meanwhile, the tourism industry has consumed a considerable amount of water, energy, and disposable products owing to the nature and characteristics of its services, resulting in serious contamination of the atmosphere, oceans, soil, biota, freshwater, etcetera; besides, the purchase of raw materials, manufacture of tourism products, and disposal of used products has also damaged the ecological environment (Chu \& Chung, 2016; Gössling et al., 2012; Han \& Haejin, 2015). Although the Chinese government has paid much attention to environmental protection since 1995, the tradeoff between environmental problems and economic growth is still the most delicate question that it currently faces (Chen, Wang, \& Feng, 2016).

With the popularization of environmental protection, consumers are increasingly willing to change their consumption lifestyles by exhibiting more eco-friendly behavior and willingness-to-pay for green products to reduce environmental pollution. For example, consumers in the United Kingdom (U.K.), spent GBP 38 billion in their pursuit of green alternatives ${ }^{1}$. As indicated by Budeanu and Chesworth (2007) and Su and Swanson (2017), tourists' demands for green tourism have been growing in the past few decades. This implies that the green operation of firms is becoming essential to maintaining enterprise competitiveness or capturing a greater market share and many tourism enterprises have been striving to invent new eco-friendly products to attract and target more tourists (Chen \& Chai, 2010; Han \& Haejin, 2015). However, green tourism enterprises face a significantly higher investment and a longer payback period than traditional ones. Additionally, some local governments have paid more attention to economic indicators than environmental impact. Consequently, it is a matter of utmost urgency for the Chinese government to make sure that the public responds positively to the sustainable development policies by coming up with some effective mechanisms. Considering this background, this paper is dedicated to answering the following research questions:

(1) How does the central government motivate tourism stakeholders to select green tourism?

\footnotetext{
1Rodionova Z., Independent (2014) "Ethical spending surges to \$38bn in UK as consumers look to green alternatives."http://www.independent.co.uk/news/business/news/ethical-spending-surges-to-38bnin-uk-asconsumers-look-to-green-alternatives-a6790956.html
} 
(2) Under what conditions does each stakeholder have a stable strategy from a longterm perspective?

(3) What are the evolutionary stable strategies and corresponding conditions of the dynamic system, with and without government green supervision?

(4) How would the factors, such as green incentive intensity of local governments, brand benefit of tourism enterprises, and green preferences of tourists affect the decision of each stakeholder?

This paper proposes a dynamic evolutionary game model to address the above questions. Evolutionary game theory is the self-organization process by which a population of individual evolves into the expected distribution of individual behaviors based on participants learning (Weibull, 1997). The pivotal concept of evolutionary game theory is the evolutionary stable strategy (ESS) first proposed by Smith and Price (1973), which can be defined as a strategy $S^{*}$ satisfying two conditions: (1) $E\left(S^{*}, S^{*}\right) \geq E\left(S, S^{*}\right)$ for all $S \neq S^{*}$ and (2) $E\left(S^{*}, S\right)>E(S, S)$, where $E$ denotes the payoff function and $S$ represents the possible strategy other than $S^{*}$ (Barari et al., 2012). The replicator dynamic proposed by Taylor and Jonker (1978) is a dynamic differential analysis method, which is widely used to investigate the long-term strategic stability of stakeholders. The core idea of replicator dynamic analysis is that if one strategy gains more than the average income of other strategies during the game process, it indicates that the strategy is suitable for the evolution of the group. In other words, the strategy has stability as an invasion strategy and can evolve into a stable strategy through repeated games.

Based on the evolutionary game theory, we first discuss the ESS concerning green innovation for each stakeholder. Then, we analyze the ESS between tourism enterprises and tourists, with and without consideration of the local governments' green supervision policy. The research results show that the decisions of stakeholders can interact with each other under certain conditions. It is worth noting that local governments' supervision behavior cannot directly affect the purchasing decision of tourists, but it can indirectly drive tourists to accept the green tourism pattern by encouraging tourism enterprises to sell green products. The findings also highlight that enhancing brand benefit of tourism enterprises and/or green preference of tourists is an extremely useful method to stimulate stakeholders to adopt green tourism. Through the numerical experiment, we conclude that the initial states of stakeholders taking part in 
green activities can only affect the short-term decisions of all participants, whereas the evolutionary stable conditions can determine the decision making of each stakeholder from a long-term perspective. Moreover, we propose a green incentive mechanism and identify the optimal conditions of green incentive intensity to achieve the ideal green tourism pattern. We further suggest that the government should first implement green incentive mechanism in the areas where the scale of tourism is relatively small. The management implications could benefit the development of modern tourism industry, as well as promote the implementation of the government's sustainable development policies.

The paper starts with a review of relevant literature on sustainable tourism and dynamic game theory. The second part describes the basic model and its corresponding assumptions. The third part presents the ESS for each stakeholder and its corresponding stable conditions, and numerical examples are employed to discuss the impacts of some key parameters. The conclusions and managerial insights for sustainable tourism development are proposed in the final section of the paper.

\section{Literature review}

This paper draws on, and contributes to, two distinct streams of literaturesustainable tourism and dynamic game theory.

\section{Sustainable tourism}

Since China vowed to incorporate sustainable development into its policies in 1995, it has become a buzzword in the operational management field on which many researchers have focused (Huang et al., 2008; Lu \& Nepal, 2009; Liu et al., 2014). As one of the main driving forces of China's economic development, tourism has led to some environmental issues (Tang et al., 2011). Some researchers have investigated green consumption from the perspectives of tourists, firms, and society, and suggested that tourism enterprises should shift their focus from the supply side to the demand side for sustainable development (Budeanu \& Chesworth, 2007; Kastenholz, 2004; Swarbrooke, 1999). With the general trend of sustainable development, the tour operators have faced enormous pressure related to environmental protection in the past ten years, exerted by government, economics, culture, and society (Chu \& Chung, 2016). Roberts and Tribe (2008) indicated that small tourism enterprises automatically 
contribute to sustainable tourism development by offering personalized tours. Some scholars (Saarinen, 2014; Zhao, Chen, \&Liu, 2015) have confirmed that government regulation is a useful method that encourages civil enterprises to turn traditional tourism into sustainable tourism to a large extent. A large number of studies have investigated the characteristics of green guests, motivations for green consumption, and the impacts of green attributes on tourist satisfaction (Peattie, 2010; Kasim, 2004). Jinsoo, Hsu, Han, and Yunhi (2010) investigated how guests visit green hotels and concluded that the set of impressions made by green hotels could lead to more beneficial behavioral intentions. Kim, Hlee, and Joun (2016) stated that the green practices of hotels could enhance customers' satisfaction, but that this happens only through perceiving the relative quality of service. Lin and Huang (2012) confirmed that environmentally friendly consumers express stronger favor for, and higher satisfaction with, green products. Moreover, anthropocentric or eco-centric values could significantly influence people's attitudes towards sustainable tourism development (Xu \& Fox, 2014). Some studies in environmental psychology have proved that increasing the environmental awareness of consumers would influence their purchasing behavior (see Bagozzi \& Dholakia, 2006; Miller et al., 2010; Chen \& Tung, 2014). Additionally, the theme of "attitude-behavior gap" has also been widely studied by Vermeir and Verbeke (2006). They claimed that people's positive attitudes (intentions) do not lead to the actual purchase of green items or participation in environmental activities. As for tour firms, they often make production plans on the basis of market demand and operational costs. Therefore, it is more realistic to consider the purchase behavior of tourists while analyzing the decision making of tourism enterprises. As Buckley (2012) found, mainstream tourism was still far from implementing sustainable development. So far, few researches have explored the incentive mechanism that could motivate tourism stakeholders to implement green innovation.

\section{Dynamic game theory}

Dynamic game theory mainly studies the decision behavior among participants by considering the time factor in sequential, differential, evolutionary, repeated, and stochastic games. This theory has been widely used to investigate the pricing decisions in the field of operational management (Baldacci et al., 2017; Chen et al., 2016). Some researchers have employed the dynamic game method to discuss the game behavior 
among tourism stakeholders (Huang et al., 2010; Yang et al., 2015; Zyl, 2012). Their research results have shown that tour operators often consider the rivals' decision behavior when they are creating their operational schemes. Wie (2005) built a dynamic game model to explore the capacity investment strategy in the cruise line industry. He found the open-loop Nash equilibrium solution by using Pontryagin's maximum principle. García and Tugores (2006) constructed a vertical differential game model by considering both quality and price competition of hotels in a duopoly market and found the optimal service quality and price decisions. Blanco, Lozano, and Rey-maquieira (2009) utilized a dynamic approach to analyze the voluntary environmental contributions in the tourism industry. They indicated that the stable equilibria with (without) voluntary environmental initiatives could coexist under certain conditions. $\mathrm{Li}$ (2011) applied a sequential game model to discuss the strategic interaction between competitive and complementary destinations, and suggested that rational decision makers should choose moderate strategies instead of aggressive ones for sustainable development. Guo et al. (2013) and Ling et al. (2014) explored the optimal pricing strategy for hotels when hotel managers operate an online channel by cooperating with a third-party website. Both of them proposed a coordination strategy for the hotels and third party website to achieve a win-win situation. By comparing the sequential game with price competition, Yang, Ji, and Chen (2016) investigated the pricing setting in a tourism supply chain consisting of a hotel and an online travel agency. Encarnação et al. (2016) utilized evolutionary game theory to discuss the complex interactions among state, business, and civil sectors. They highlighted that public sectors act as significant driving forces in the civil sectors' shifting. Zhang and Weatherford (2017) applied the dynamic pricing method to the hotel industry for network revenue management. The above studies have shown that taking the time factor into account is more in line with reality due to the complexity and changeability of tourism problems. However, the majority of the above studies investigated the issues of dynamic pricing or strategic interaction in tourism industry by considering one or two stakeholders and ignoring the government. Our research is different from the previous studies mentioned above in that it focuses on stability analysis of green innovation strategy among three key tourism stakeholders by using a long-term perspective.

Some of the aforementioned studies do consider the dynamic game behavior among stakeholders but most of them assume that the participants are completely 
rational. To the best of our knowledge, this is the first time that a tripartite game of the type developed in Santos et al. (2016) and Encarnação et al. (2016) has been applied to green tourism innovation that involves local governments, tourism enterprises, and tourists by taking a long-term perspective. We establish a tripartite evolutionary game model to explore the incentive mechanism for sustainable tourism by introducing the green certification scheme ${ }^{2}$ (Dunk, Gillespie, \& Macleod, 2016). Particularly, we discuss the strategy stability for each stakeholder, regarding the choices of game members as a gradual learning process owing to their long-term imitative behavior (Blanco, Lozano, \& Rey-maquieira, 2009). On the basis of the triple bottom line (TBL) of economic responsibility, environmental responsibility, and social responsibility (Elkington, 1998), we incorporate green policy support of central government, brand benefit of tourism enterprises, and the green preference of tourists into our models, and analyze the strategic interaction of green innovation among the three key stakeholders.

\section{Model description}

This section first describes the model assumptions and notation. Then, the payoff of stakeholders is proposed. Based on the payoff, the corresponding replicator dynamic equations of participants are finally established.

\section{Model Assumption}

In China, the government often represents public interest, carrying out public governance and allocating public resources within its administrative jurisdiction. As Huang \& Chen (2005) put it, the overuse of common resources would result in the tragedy of the commons (Hardin, 1968) without effective regulation and a perfect legal system. To encourage enterprises to adopt green operational pattern, local government departments (e.g., local environmental protection bureau, commodity inspection bureau, etc.) need to invest a certain amount of resources to supervise enterprises' green production and carbon emission. Without loss of generality, we assume the given green standard $g_{0}=0$, which is used to distinguish tourism enterprises' green behavior by government (Zhu \& He, 2016). When the green degree of tourism firms' products is

\footnotetext{
2The green certification scheme is used to judge whether enterprises carry out the green operation mandated by government. When the enterprises are recognized as green enterprises, the government will provide them some subsidy. Otherwise, they will be given an appropriate punishment.
} 
green $(g>0)$, the government supervision departments (hereafter local governments) will reward the firms with corresponding green subsidy $T$ per unit product. However, when the products are identified as non-green $(g<0)$, the firms will be punished with penalty $T$ per unit product (we call $T$ as green incentive intensity). Owing to the positive green supervision behavior, local governments can obtain additional benefit $U_{g}$ (hereafter green policy support) by paying an additional supervision cost $C_{g}$. The green policy support is often provided by central government in various forms, such as financial support and/or affirming the local governments' work performance due to the positive responses to the sustainable development policy. Obviously, green policy support is related to the local governments' green supervision behavior and the parameters $U_{g}$ and $C_{g}$ are independent of the market demand ${ }^{3} Q$. If the local governments do not implement the green supervision, they will not obtain this support from central government and the benefit will be 0 or $-C_{w}$, depending on the decision of the tourism enterprises $\left(C_{w}\right.$ denotes additional environmental governance cost of local governments due to the contamination caused by traditional tourism).

In the current paper, it is assumed that the tourism enterprises have the characteristics of rational economic agents, that is., they pursue maximum profit. On the one hand, tourism enterprises consider their own business objectives and marketing plans based on production cost and sales revenue. On the other hand, they are sensitive to the consumers' perception and government regulations. In practice, many enterprises believe that undertaking social responsibility can benefit them owing to the unquantifiable extra boost it gives to their brands (Panda, Modak, Basu, \& Goyal, 2015; Su \& Swanson, 2017). Thus, securing the long-run support from stakeholders towards the corporations has become a significant issue(Serra-Cantallops, Peña-Miranda, Ramón-Cardona, \& Martorell-Cunill, 2017). Accordingly, if the tourism firms adopt a green innovation strategy (undertaking social responsibility), they can obtain additional average expected benefit $b$ (hereafter brand benefit) per unit product, which may be influenced by public admiration. We focus here on the average value of the brand benefit due to its complexity, which could be obtained by survey research, and the public here does not only mean tourists but also local residents and other relevant

\footnotetext{
${ }^{3}$ The supervision cost of Government is often presented for a period of time, such as a month. So, we consider here the demand for one month, which can be regard as a constant due to relative short-term stability and predictability.
} 
stakeholders. As an example, the local residents would like to recommend their admired tourism enterprises to the tourists. Thus, the parameter $b$ is related to the firms' green decision but is independent of the tourists' purchase behavior. Owing to green production and/or carbon emission control, green firms have to pay additional cost $c$. Without loss of generality, we normalize the unit production cost of non-green products $c_{0}=0$. Besides, tourism enterprises can obtain corresponding subsidy $T Q$ or penalty $-T Q$ from local governments, depending on their decisions during the sales period. They can also earn total sales revenue $\left(p_{1} Q\right.$ or $p_{2} Q$ or 0$)$ under the purchasing behavior of tourists, where $p_{1}$ and $p_{2}$ are the unit prices of green products and nongreen products, respectively. It is reasonable to assume $p_{1}>p_{2}$ due to the additional cost incurred for green products.

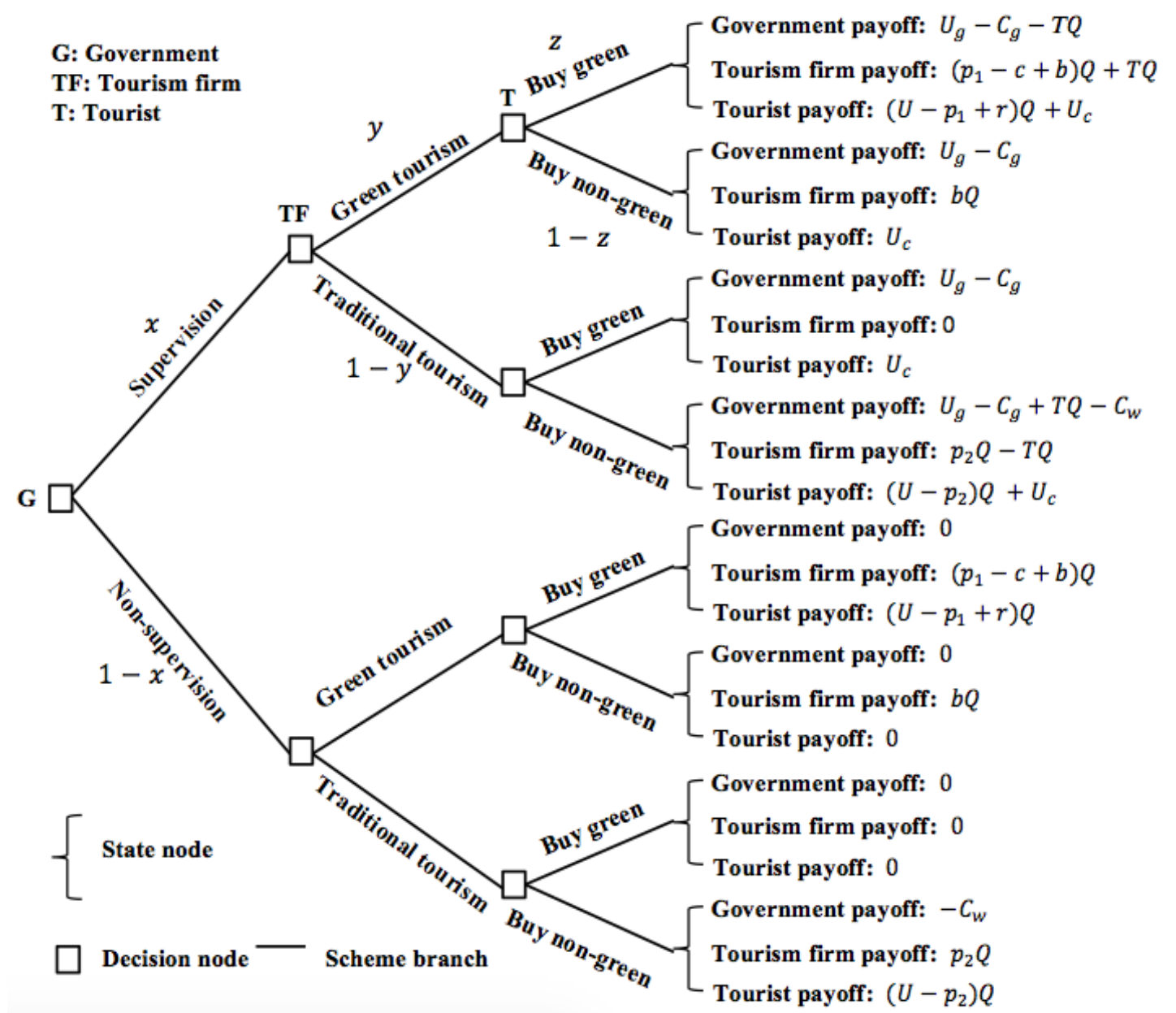

Fig. 1. Payoff of stakeholders

Note: Decision Tree is a decision support tool that uses a tree-like graph or model of decisions and their possible consequences, including decision nodes, scheme branches, chance event outcomes (state nodes), and payoff (utility). 
As for tourists, they can get basic value $U$ if they purchase green products. Many studies have demonstrated that consumers buying green products usually confirm that green products can bring them additional green preference benefit (thereafter green preference) $r \geq 0$ owing to their environmental awareness (Jinsoo et al., 2010; Lin \& Huang, 2012; Zhu \& He, 2016). Particularly, if local governments adopt green supervision strategy that can improve ecological environment, all citizens, including tourists, can get additional social environmental benefit $U_{c}$ (i.e., good health). Consequently, the tourists can acquire total product revenue $\left(U-p_{1}+r\right) Q$ during the sales period and the social environmental benefit $U_{c}$ when they buy green products under the condition that local governments implement green supervision. They can obtain revenue $\left(U-p_{2}\right) Q$ by buying traditional tourism products without supervision (to make economic sense, we assume $U>p_{2}$ but $p_{1}$ may be bigger than $U$ due to the additional cost of green product). Based on the above assumptions, we can obtain the payoff of tourism stakeholders shown in Fig. 1.

\section{Model framework}

According to the aforementioned replicator dynamic analysis method, we let $x$ denote the proportion of the population of local governments implementing green supervision; so, $(1-x)$ represents the proportion adopting a non-supervision strategy. Likewise, the rate of adoption of green) tourism strategy and traditional tourism strategy by enterprises is $y$ and $(1-y)$, respectively. Furthermore, $z$ and $(1-z)$ stand for the proportion of the tourist population purchasing green tourism products and not purchasing them, respectively. From the foregoing payoff in Fig. 1, the expected and average revenue of local governments can be expressed by the following equations.

$$
\left\{\begin{aligned}
\begin{array}{r}
E \Pi_{g}^{x}=y\left(z\left(U_{g}-C_{g}-T Q\right)+(1-z)\left(U_{g}-C_{g}\right)\right)+(1-y)\left(z\left(U_{g}-C_{g}\right)\right. \\
\\
\left.\quad+(1-z)\left(U_{g}+T Q-C_{g}-C_{w}\right)\right)
\end{array} \\
E \Pi_{g}^{1-x}=y(z \cdot 0+(1-z) \cdot 0)+(1-y)\left(z \cdot 0+(1-z) C_{w}\right) \\
E \bar{\Pi}_{g}=x \Pi_{g}^{x}+(1-x) \Pi_{g}^{1-x}
\end{aligned}\right.
$$

From Eq. (1), we can obtain the replicator dynamic equation of local governments' decision making, as shown below:

$$
F(x)=\frac{d x}{d t}=x\left(E \Pi_{g}^{x}-E \bar{\Pi}_{g}\right)=x(1-x)\left[U_{g}-C_{g}+(1-y-z) Q T\right]
$$

where $F(x)$ represents the rate of change of local governments selecting supervision strategy. When $F(x)<0$, it means the proportion $x$ of local governments 
choosing supervision strategy evolves to 0 , whereas $F(x)>0$ indicates that $x$ evolves to 1 over time. It can be found that the rate of change of strategy is not only related to the probability but also correlated to the gap between expected revenue on adopting supervision strategy and the average expected revenue.

Similar to the modeling process for the replicator dynamic equation of local governments, we can obtain the expected and average revenue of tourism enterprises and their replicator dynamic equation, as shown in Eqs. (3) and (4).

$$
\begin{gathered}
\left\{\begin{array}{r}
E \Pi_{f}^{y}=x\left(z\left(p_{1}-c+b+T\right) Q+(1-z) b Q\right) \\
\quad+(1-x)\left(z\left(p_{1}-c+b\right) Q+(1-z) b Q\right) \\
E \Pi_{f}^{1-y}=x(1-z)\left(p_{2}-T\right) Q+(1-x)(1-z) p_{2} Q \\
E \bar{\Pi}_{f}=y \Pi_{f}^{y}+(1-y) \Pi_{f}^{1-y}
\end{array}\right. \\
F(y)=\frac{d y}{d t}=y\left(E \Pi_{f}^{y}-E \bar{\Pi}_{f}\right)=y(1-y) Q\left[T x+z\left(p_{2}+p_{1}-c\right)+b-p_{2}\right]
\end{gathered}
$$

Following the same logic as used earlier, the expected and average revenue of tourists are given as follows:

$$
\left\{\begin{array}{l}
E \Pi_{c}^{z}=x\left(y\left(\left(U-p_{1}+r\right) Q+U_{c}\right)+(1-y) U_{c}\right)+(1-x)\left(y\left(U-p_{1}+r\right) Q\right) \\
E \Pi_{c}^{1-z}=x\left(y U_{c}+(1-y)\left(\left(U-p_{2}\right) Q+U_{c}\right)\right)+(1-x)(1-y)\left(U-p_{2}\right) Q \\
E \bar{\Pi}_{c}=z \Pi_{c}^{z}+(1-z) \Pi_{c}^{1-z}
\end{array}\right.
$$

Consequently, the replicator dynamic equation concerning tourists' strategy can be given by

$$
F(z)=\frac{d z}{d t}=z\left(E \Pi_{c}^{z}-E \bar{\Pi}_{c}\right)=(1-z) z Q\left[y\left(2 U+r-p_{1}-p_{2}\right)-\left(U-p_{2}\right)\right]
$$

By observing the replicator dynamic equations (2), (4), and (6) of stakeholders, we can obtain Observation 1 below:

\section{Observation 1.}

(i) The local governments' supervision policy significantly affects the green innovation decision of tourism enterprises, but it cannot directly affect the purchasing behavior of tourists. The decisions of tourism enterprises and/or tourists can impact local governments'strategy to some extent.

(ii) The social environmental benefit $U_{c}$ and additional environmental governance cost $C_{w}$ cannot impact the decisions of participants.

Observation 1 shows the strategic interaction among stakeholders and indicates that it is not necessary for participants to consider all factors because some of them, 
such as social environmental benefit and additional environmental governance cost, cannot affect the stability of the dynamic system from a long-term perspective. In reality, the government does regard the theory that controlling pollution before it occurs will save disposal costs later as an advanced environmental management concept of sustainable development.

\section{Model analysis}

In this section of the paper, we will explore the long-term stable states of the strategies of stakeholders and the ESS of the dynamic system. We first analyze the strategy stability of each stakeholder by utilizing dynamic differential analysis method.

\section{Strategy stability analysis of local governments}

From Observation 1, we know that local governments' decision making is affected by the strategies of tourism enterprises and tourists. To facilitate analysis, we let $y^{\prime}=$ $\frac{U_{g}-C_{g}+Q T(1-z)}{Q T}$ or $z^{\prime}=\frac{U_{g}-C_{g}+Q T(1-y)}{Q T}$ represent the roots of $F(x)=0$, except at $x=0$ and $x=1$. It can be easily found that $y^{\prime}$ and $z^{\prime}$ have symmetry, so we take $y^{\prime}$ as an example to analyze the strategy stability of local governments.

When $y=y^{\prime}$, it's obvious that $F(x) \equiv 0$ is right for any $x$. It means that any regulatory strategy of local governments is a stable strategy at this time. The initial strategy chosen does not change over time, that is, green tourism cannot be promoted over time. When $y \neq y^{\prime}$, we can obtain two possible evolutionary stable points with $F(x)=0$, at $x_{1}=0$ and $x_{2}=1$. By taking the first derivative of $F(x)$ with respect to $x$, we obtain the following equation.

$$
F^{\prime}(x)=(1-2 x)\left[U_{g}-C_{g}+(1-y-z) Q T\right]
$$

Owing to $0 \leq y, z \leq 1$, we can derive that $(1-y-z) Q T \geq-Q T$. From Eq. (7), it can be concluded that when $U_{g}>C_{g}+Q T$, then $U_{g}-C_{g}+(1-y-z) Q T>0$, which results in $\left.F^{\prime}(x)\right|_{x=1}<0$ for any $y$ and $z$. Likewise, when $U_{g}>C_{g}+Q T y$, it implies that $U_{g}-C_{g}-y Q T+(1-z) Q T>0$. Therefore, we can get $\left.F^{\prime}(x)\right|_{x=1}<$ 0 for any $z$. Furthermore, when $C_{g}-(1-z) Q T<U_{g}<C_{g}+Q T y$, suppose that $y<\min \left(1, y^{\prime}\right)$; then, it can be easily found that $\left.F^{\prime}(x)\right|_{x=1}<0$; however, if $\max \left(0, y^{\prime}\right)<y<1$, we can work out that $\left.F^{\prime}(x)\right|_{x=0}<0$. Last, when $U_{g}<C_{g}-$ $(1-z) Q T$, it can be proved that $U_{g}-C_{g}+(1-z) Q T-y Q T<0$, which implies that $\left.F^{\prime}(x)\right|_{x=0}<0$ for any $y$; when $U_{g}<C_{g}-Q T$, we can deduce that $U_{g}-C_{g}+$ 
$(1-z) Q T-y Q T<0$ for any $y$ and $z$. In this setting, $\left.F^{\prime}(x)\right|_{x=0}<0$ is right for any $y$ and $z$. We summarize the above conditions and attain the Proposition 1 below:

\section{Proposition 1.}

(i) When $U_{g}>C_{g}+Q T, x=1$ is the ESS for any $y$ and $z$.

(ii) When $U_{g}>C_{g}+$ QTy, $x=1$ is the ESS for any $z$.

(iii) When $C_{g}-(1-y) Q T<U_{g}<C_{g}+Q T y$, if $y<\min \left(1, y^{\prime}\right), x=1$ is the ESS; if $\max \left(0, y^{\prime}\right)<y<1, x=0$ is the ESS.

(iv) When $U_{g}<C_{g}-(1-y) Q T, x=0$ is the ESS for any $z$.

(v) When $U_{g}<C_{g}-Q T, x=0$ is the ESS for any $y$ and $z$.

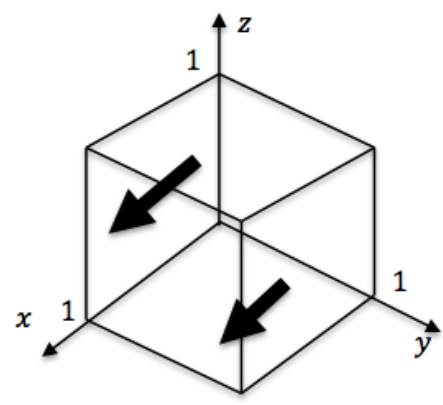

(a)

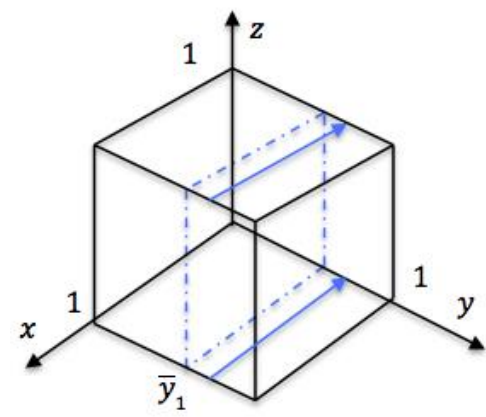

(c)

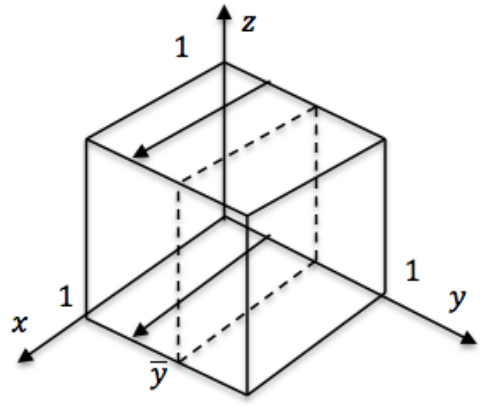

(b)

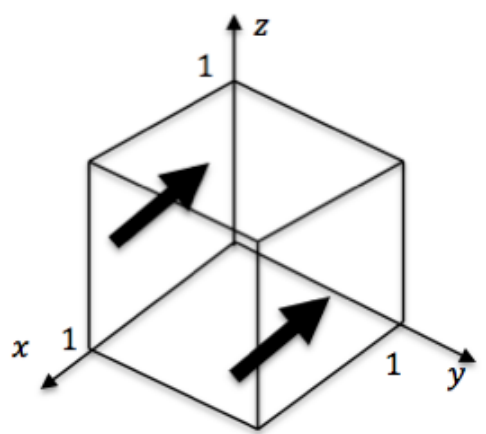

(d)

Fig. 2. Phase diagrams for the strategy of local governments

Note: (a) $U_{g}>C_{g}+Q T$; (b) $y<\bar{y}=\frac{U_{g}-C_{g}}{Q T}$; (c) $y>\bar{y}_{1}=\frac{U_{g}+Q T-C_{g}}{Q T}$; (d) $U_{g}<C_{g}-Q T$. The direction of the arrow represents the direction of the strategy's evolutionary trend.

We utilize Fig. 2 to facilitate the observation of the evolutionary trend by readers. As Proposition 1(i) shows, when local governments can acquire sufficient green policy support by implementing supervision policy, they would promote green tourism pattern without considering the behaviors of tourism enterprises and tourists (see Fig. 2[a]). For example, central government provides a sufficiently high financial support to the local governments. Proposition 1(ii) indicates that the strategy of tourism enterprises 
can independently affect the strategy stable states of local governments under certain condition (see Fig. 2[b]). Furthermore, the fewer tourism firms adopt green tourism innovation, the more likely it is that local governments adopt the green supervision strategy. As a result, it is beneficial for tourism firms to adopt green tourism pattern actively during the initial phase of green tourism market, when there are relatively few green enterprises. Proposition 1(iii) implies that when $U_{g}$ is moderate, the decisions of tourism firms and tourists will jointly affect the strategy stability of local governments. Specifically, the more the number of tourism enterprises that adopt green tourism, the higher is the motivation among local governments to implement green supervision. Proposition 1(iv) demonstrates that when green policy support is relatively low $\left(U_{g}<C_{g}-(1-y) Q T\right)$, the local governments may not consider the decision of tourists (see Fig. 2[c]). As Proposition 1(v) shows, if green policy support is very low, the local governments have no motivation to implement green incentive mechanism (see Fig. 2[d]). At this time, the central government should provide higher financial support and/or strengthen the work performance management of local governments.

\section{Strategy stability analysis of tourism enterprises}

According to Eq. (4), we can explicitly discover that the decisions of local governments and tourists jointly influence the tourism enterprises' decision making. For the sake of convenience, we set $x^{\prime}=\frac{z\left(c-p_{1}-p_{2}\right)+p_{2}-b}{T}$ and $z^{\prime \prime}=\frac{p_{2}-b-T x}{p_{1}+p_{2}-c}$, both of which are the roots of $F(y)=0$, except at $y=0$ and $y=1$.

If $x=x^{\prime}$ or $z=z^{\prime \prime}$, then $F(y) \equiv 0$ is suitable for any $y$. This means that any green innovation strategy of tourism enterprises is a stable strategy. If $x \neq x^{\prime}$ and $z \neq$ $z$ ", from the first derivative of $F(y)$, the following equation can be obtained.

$$
F^{\prime}(y)=(1-2 y) Q\left[T x+z\left(p_{2}+p_{1}-c\right)+b-p_{2}\right]
$$

It is assumed that the green innovation cost is not too high, that is, $c \leq p_{1}+p_{2}$, or else no stakeholder, including the government, will take part in the green activity,. That is to say, we do not consider the case $c>p_{1}+p_{2}$. Observing Eq. (8), if $b>p_{2}$, we can explicitly derive that $\left[T x+z\left(p_{2}+p_{1}-c\right)+b-p_{2}\right]>0$ is right for any $x$ and $z$; then, $\left.F^{\prime}(x)\right|_{x=1}<0$. When $b<p_{2}$, if $z\left(p_{2}+p_{1}-c\right)+b>p_{2}$, then $\left[T x+z\left(p_{2}+p_{1}-c\right)+b-p_{2}\right]>0$ for any $x$, which implies $\left.F^{\prime}(x)\right|_{x=1}<0$; likewise, if $T x+b>p_{2}$, we also can derive that $\left.F^{\prime}(x)\right|_{x=1}<0$ for any $z$. In addition, when $z\left(p_{2}+p_{1}-c\right)+b<p_{2}$ or $T x+b<p_{2}$, we can prove that if $x<$ 
$\min \left(1, x^{\prime}\right)$ or $z<\min \left(1, z^{\prime \prime}\right)$, then $\left.F^{\prime}(x)\right|_{x=0}<0$; however, if $\max \left(0, x^{\prime}\right)<x<1$ or $\max \left(0, z^{\prime \prime}\right)<z<1$, we get $\left.F^{\prime}(x)\right|_{x=1}<0$. According to the above conditions that ensure $\left.F^{\prime}(x)\right|_{x=1}<0$, we can obtain Proposition 2:

\section{Proposition 2.}

(i) When $b>p_{2}, y=1$ is the ESS for any $x$ and $z$.

(ii) When $b<p_{2}$, if $z\left(p_{2}+p_{1}-c\right)+b>p_{2}, y=1$ is the ESS for any $x$; if $T x+b>p_{2}, y=1$ is the ESS for any $z$.

(iii) When $z\left(p_{2}+p_{1}-c\right)+b<p_{2}$, if $x<\min \left(1, x^{\prime}\right), y=0$ is the ESS; if $\max \left(0, x^{\prime}\right)<x<1, y=1$ is the ESS.

(iv) When $T x+b<p_{2}$, if $z<\min \left(1, z^{\prime \prime}\right), y=0$ is the ESS; if $\max \left(0, z^{\prime \prime}\right)<z<$ $1, y=1$ is the ESS.

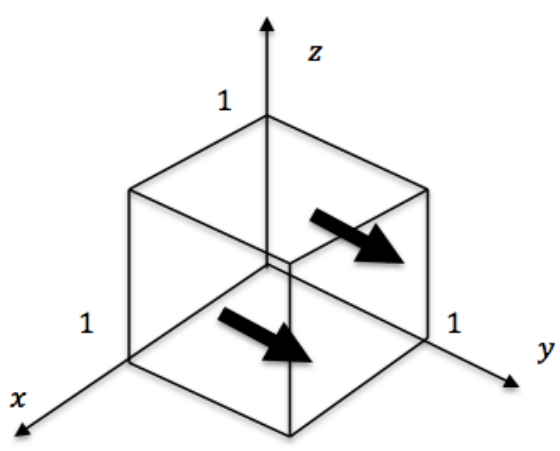

(a)

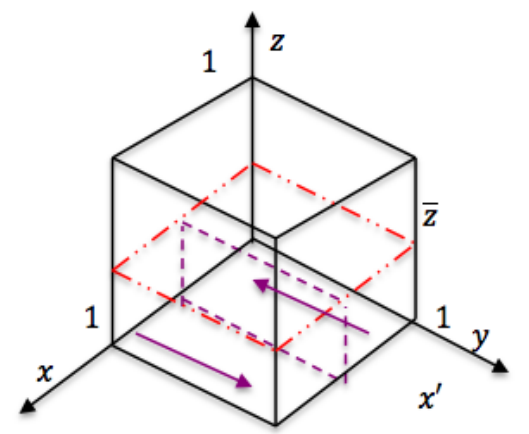

(c)

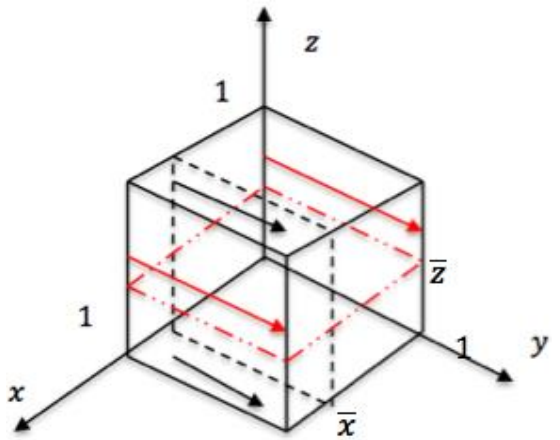

(b)

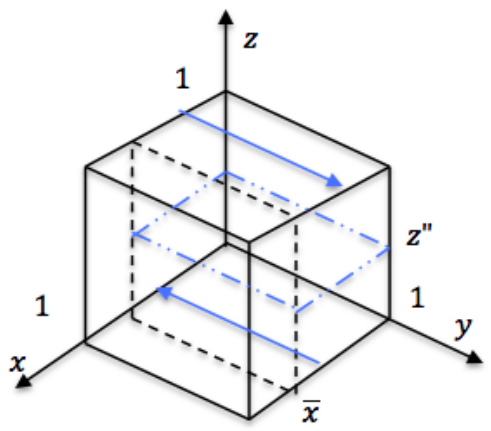

(d)

Fig. 3. Phase diagram of the strategy of tourism enterprises

Note: (a) $b>p_{2}$; (b) $b<p_{2}$ and $x>\bar{x}=\frac{p_{2}-b}{T}$ or $z>\bar{z}=\frac{p_{2}-b}{\left(p_{2}+p_{1}-c\right)}$; (c) $z<\bar{z}=\frac{p_{2}-b}{\left(p_{2}+p_{1}-c\right)}$, wherein $x^{\prime}=\frac{z\left(c-p_{1}-p_{2}\right)+p_{2}-b}{T}$; (d) $x<\bar{x}=\frac{p_{2}-b}{T}$, wherein $z^{\prime \prime}=\frac{p_{2}-b-T x}{p_{1}+p_{2}-c}$. The direction of the arrow direction represents the direction of the strategy's evolutionary trend.

Fig. 3 shows the phase diagram of the strategy of tourism enterprises under different conditions. Proposition 2(i) reveals that tourism enterprises would like to 
adopt green innovation strategy spontaneously as long as the brand benefit is greater than the price of the non-green product (see Fig. 3[a]). As a result, local governments can improve brand benefit to stimulate tourism firms to adopt the green tourism pattern instead of only using monitoring policies. For example, local governments can grant tourism firms green certifications to enhance their brand image. Proposition 2(ii) indicates that when brand benefit of tourism enterprises is moderate, the local governments' strategy or tourists' purchasing strategy can independently encourage tourism enterprises to implement green innovation when the proportion of their positive strategies is high enough (see Fig. 3[b]). From Proposition 2(iii) and (iv), we conclude that when the brand benefit is relatively low, the decision of tourism enterprises is affected by the strategies of local governments and tourists (see Fig. 3[c] and [d]). Only under the condition that the rates of local governments adopting green supervision and tourists purchasing green products are both high enough will the tourism firms select green tourism.

\section{Strategy stability analysis of tourists}

It is easy to find that the decision making of tourists is only related to the decision of tourism enterprises, according to Eq. (6). It clearly shows that tourists' purchase decision is made on the basis of their own utility but independent of the local governments' decision, which is more consistent with the reality. For the sake of simplicity of representation, we define $y^{\prime \prime}=\frac{U-p_{2}}{2 U+r-p_{1}-p_{2}}$, which is one of the roots of $F(z)=0$, except at $z=0$ and $z=1$.

If $y=y^{\prime \prime}$, then $F(z) \equiv 0$ is suitable for any $z$. This implies that any purchasing strategy of the tourists is a stable strategy, that is, the strategy chosen will not change over time. If $y \neq y^{\prime \prime}$, we can obtain two possible stable points: $z_{1}=0$ or $z_{2}=1$ from $F(z)=0$. Taking the first derivative of $F(z)$ yields the following equation.

$$
F^{\prime}(z)=(1-2 z) Q\left[y\left(2 U+r-p_{1}-p_{2}\right)-\left(U-p_{2}\right)\right]
$$

Observing Eq. (9), we derive that if $2 U+r<p_{1}+p_{2}$, together with given condition $U>p_{2}$, then $\left[y\left(2 U+r-p_{1}-p_{2}\right)-\left(U-p_{2}\right)\right]<0$ is right for any $y$. It is easy to check that $\left.F^{\prime}(z)\right|_{z=0}<0$. When $2 U+r>p_{1}+p_{2}$, if $y<\min \left(1, y^{\prime \prime}\right)$, we obtain that $\left[y\left(2 U+r-p_{1}-p_{2}\right)-\left(U-p_{2}\right)\right]<0$, resulting in $\left.F^{\prime}(z)\right|_{z=0}<0$; However, when $\max \left(0, y^{\prime \prime}\right)<y<1$, then $\left[y\left(2 U+r-p_{1}-p_{2}\right)-\left(U-p_{2}\right)\right]>0$, leading to $\left.F^{\prime}(z)\right|_{z=1}<0$. Accordingly, Proposition 3 can be obtained. 


\section{Proposition 3.}

(i) When $2 U+r<p_{1}+p_{2}, z=0$ is the ESS for any $y$.

(ii) When $2 U+r>p_{1}+p_{2}$, if $y<\min \left(1, y^{\prime \prime}\right), \quad z=0$ is the ESS; if $\max \left(0, y^{\prime \prime}\right)<y<1, z=1$ is the ESS.

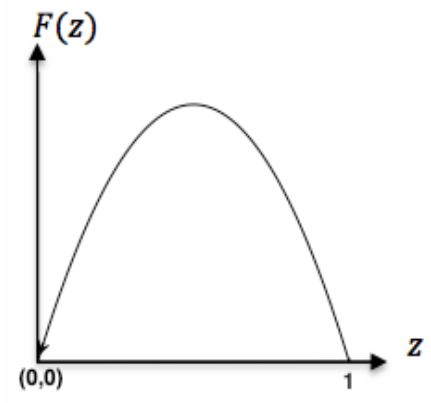

(a)

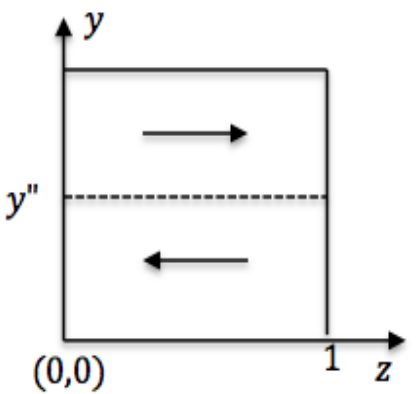

(b)

Fig. 4. Phase diagram of the strategy of tourists

Note: (a) $2 U+r<p_{1}+p_{2}$; (b) $2 U+r>p_{1}+p_{2}$, where $y^{\prime \prime}=\frac{U-p_{2}}{2 U+r-p_{1}-p_{2}}$. The direction of the arrow represents the direction of the strategy's evolutionary trend.

The readers can understand the strategy evolutionary trend of tourists with the assistance of Fig. 4. From Proposition 3(i), it is shown that when green preference of tourists is relatively small, it cannot motivate the tourists to accept green tourism pattern, which would lead more tourism enterprises to adopt the traditional tourism strategy (see Fig. 4[a]). This implies that the green preference of consumers is an important incentive that can stimulate tourism enterprises to conduct green innovation. Increasing the guests' willingness to pay for green products is significant for developing sustainable tourism. Proposition 3(ii) confirms that when tourists have a slightly higher green preference, the green tourism strategy of firms is the critical factor that encourages the tourists to accept green tourism. Concretely, it is more likely for tourists to choose green tourism pattern if there are more green tourism firms (see Fig. $4[\mathrm{~b}]$ ).

\section{ESS analysis among stakeholders}

According to the above strategy stability analysis of each stakeholder, we can explicitly say that the stable strategy varies under different circumstances. For instance, as long as the brand benefit of tourism enterprises and green preference of tourists are high, the green tourism products will be accepted by all stakeholders even if local 
governments do not implement green supervision. We now discuss the ESS between tourism enterprises and tourists without the government's green supervision.

From the replicator dynamic equations (4) and (6), we can deduce that the dynamic system has the following possible equilibrium strategy set: $(0,0)(0,1)(1,0)(1,1)$. When $0<y^{\prime \prime}, z^{\prime \prime}<1,\left(y^{\prime \prime}, z^{\prime \prime}\right)$ is also a possible stable strategy. Based on the stability theorem of differential equation, when the determinant detJ and trace trJ of the Jacobi matrix satisfy the conditions: $\operatorname{det} J>0$ and $\operatorname{trJ}<0$, the strategy is an ESS (Friedman, 1991). Accordingly, we can work out the Jacobi matrix $J$ of replicator dynamic equations of tourism enterprises and tourists as follows:

$$
J=\left[\begin{array}{ll}
\frac{\partial F(y)}{\partial y} & \frac{\partial F(y)}{\partial z} \\
\frac{\partial F(z)}{\partial y} & \frac{\partial F(z)}{\partial z}
\end{array}\right]=\left[\begin{array}{cc}
(1-2 y) Q[T x+z E+A] & (1-y) y Q E \\
(1-z) z Q(B+C) & (1-2 z) Q[y(B+C)-B]
\end{array}\right]
$$

Here, the parameters are as follows: $A=b-p_{2} ; B=U-p_{2} ; C=U+r-p_{1}$; $D=p_{1}-c+b ;$ and $E=p_{2}+p_{1}-c$. From Eq. (10), we can derive the corresponding trace $\operatorname{tr} J=a_{11}+a_{22}$ and determinant det $=a_{11} a_{22}-a_{12} a_{21}$, as given below:

$$
\left\{\begin{array}{r}
\operatorname{tr} J=(1-2 y) Q[T x+z E+A]+(1-2 z) Q[y(B+C)-B] \\
\operatorname{det} J=(1-2 y)(1-2 z) Q^{2}[T x+z E+A][y(B+C)-B] \\
-(1-y) y(1-z) z Q^{2} E(B+C)
\end{array}\right.
$$

Table 1. Strategy stability and conditions of the dynamic system without government supervision

\begin{tabular}{ccccccc}
\hline & $D e t J$ & Sign & $T r J$ & Sign & Stability & Conditions \\
\hline$(0,0)$ & $-Q^{2} A B$ & + & $(b-U) Q$ & - & ESS & $A<0$ \\
$(0,1)$ & $-Q^{2} A C$ & + & $-(A-B) Q$ & - & ESS & $A>0$ and $C<$ \\
$(1,0)$ & $Q^{2} D B$ & + & $Q(D+B)$ & + & Unstable & Any condition \\
$(1,1)$ & $Q^{2} D C$ & + & $-Q(C+D)$ & - & ESS & $C>0$ \\
$\left(y^{\prime \prime}, z^{\prime \prime}\right)$ & 0 & & $-(1-y) y(1-z) z Q^{2} E(B$ & Uncertain & $\begin{array}{c}\text { Saddle } \\
\text { point }\end{array}$ & Any condition \\
\hline
\end{tabular}

Note: the $A=b-p_{2}, B=U-p_{2}, C=U+r-p_{1}, D=p_{1}-c+b$.

Suppose that local governments do not implement a green incentive mechanism. The tourism enterprises would set a sufficiently high sales price for the unit green product, that is, $p_{1}-c+b>0$ from a rational point of view. From the Jacobi matrix $J$, we can analyze the stability of the equilibrium strategy and find out the corresponding conditions shown in Table 1, where $y^{\prime \prime}$ and $z^{\prime \prime}$ are as defined in the previous 
subsection. Among them, the three points $(0,0),(1,0)$ and $(1,1)$ are asymptotic ESS of the dynamic system (corresponding to the following strategy combinations of tourism enterprises and tourists: adopt traditional tourism and buy non-green products; adopt green tourism and buy non-green or green products). The points $(0,1)$ or $\left(y^{\prime \prime}, z^{\prime \prime}\right)$ indicates that the system is in a state of temporary stability and deviates from this state over time. From Table 1, we can get Proposition 4, which shows the strategy stability between tourism enterprises and tourists.

Proposition 4. Under the precondition that local governments do not implement green incentive mechanism ( $T=0$ and/or $x=0)$, we have:

(i) When $b<p_{2}$, the $(y, z)=(0,0)$ is an ESS.

(ii) When $b>p_{2}$ and $U+r<p_{1}$, the $(y, z)=(1,0)$ is an ESS.

(iii) The $(y, z)=(0,1)$ is not an ESS under any condition.

(iv) When $r>p_{1}-U$, the $(y, z)=(1,1)$ is an ESS.

Proposition 4(i) shows that when brand benefit is relatively small, no tourism enterprises will adopt green tourism mode in the end, leading to no green products for tourists to buy. This also can explain the reason why $(y, z)=(0,1)$ is not an ESS under any condition. Proposition 4(ii) indicates that if parameter $b$ is large enough, the enterprises have the motivation to adopt green tourism. However, the tourists finally choose the non-green products due to the lower green preference. Notice that it is hard for this case to become a reality, even if we have proved it theoretically. This is because the condition $b>p_{2}$ is unlikely to happen when the tourists do not buy green products. It is easy to understand Proposition 4(iii) owing to no green products for tourists to purchase. Proposition 4(iv) highlights that when tourists have high enough green preference, the dynamic system will evolve to ESS $(1,1)$, no matter what the brand benefit is.

In order to validate the accuracy of the above analyses, we employ the numerical experiment by using the software Matlab2016 to illustrate the dynamic evolutionary process of the various strategies. Meanwhile, some important management implications can be proposed. We focus on examining the dynamic evolutionary trend and normalize the demand to 1 . The basic parameters are given by $U=10, r=1, p_{1}=12, p_{2}=$ $8, c=5$, which satisfies the condition $U+r<p_{1}$. To examine the effect of brand 
benefit, we make $b$ change over interval $[2,15.5]$ in incremental steps of 0.9. Fig. 5 depicts the evolutionary process of the dynamic system between tourism firms and tourists without government green supervision. We set basic parameters value as: $U=$ $10 ; p_{1}=14, ; p_{2}=7 ; b=8$; and $c=8$, which satisfies the condition $b>p_{2}$. We let green preference $r$ of tourists vary between 0 and 13.5, in steps of 0.9, to observe its impact on the ESS between tourism firms and tourists (see Fig. 6).

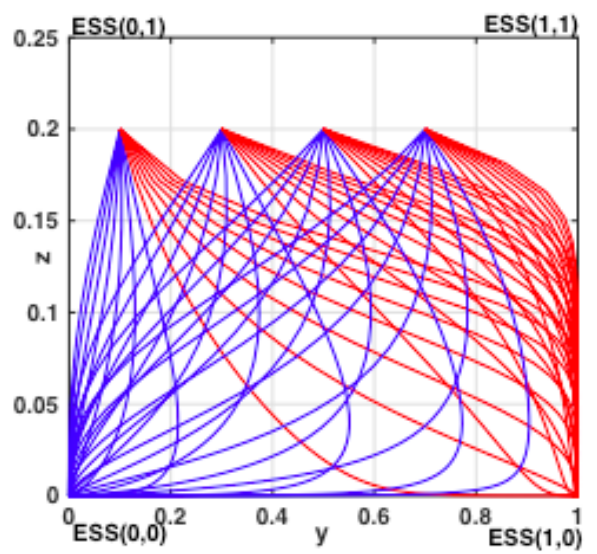

(a) $z_{0}=0.2$

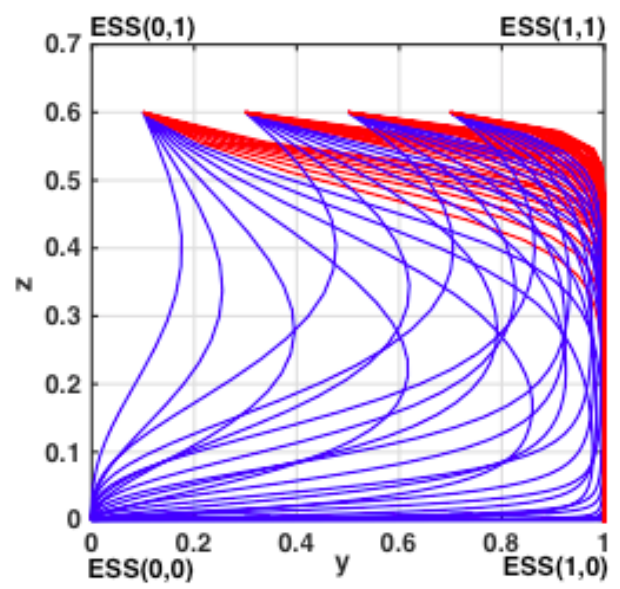

(c) $z_{0}=0.6$

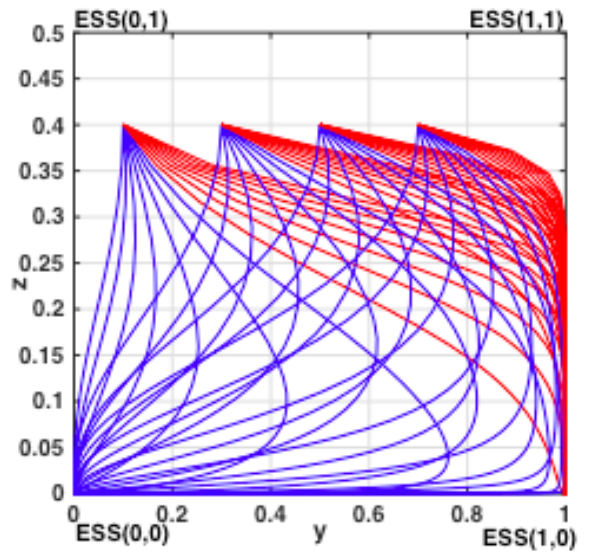

(b) $z_{0}=0.4$

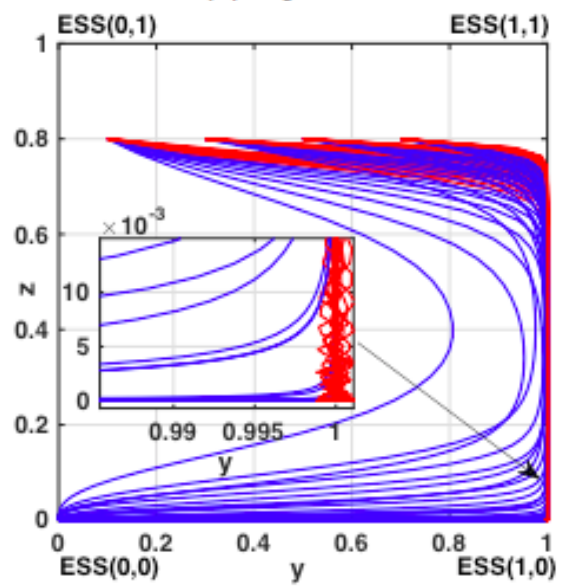

(d) $z_{0}=0.8$

Fig. 5. Dynamic evolutionary diagram of tourism enterprises and tourists by changing $b$

Fig. 5 illustrates that when brand benefit is relatively small (blue lines), the tourism enterprises finally have no motivation to implement green tourism innovation. On the contrary, when it is more than $p_{2}$ (red lines), the tour firms would adopt the green tourism innovation strategy. Furthermore, when the initial state $y_{0}$ and $z_{0}$ are both very low, the dynamic system evolves monotonically to ESS $(0,0)$; for example, $\left(y_{0}, z_{0}\right)=(0.1,0.2)$. When one (both) of them is (are) sufficiently high, the dynamic system first has an evolutionary trend toward ESS $(1,1)$ on account of the imitative 
behavior of members but finally evolves to $\operatorname{ESS}(0,0)$. This implies that the stakeholders' behavior can significantly interact with each other in the short run. Furthermore, the higher the initial rate of adoption of green behavior by the stakeholders, the stronger is their imitative behavior.

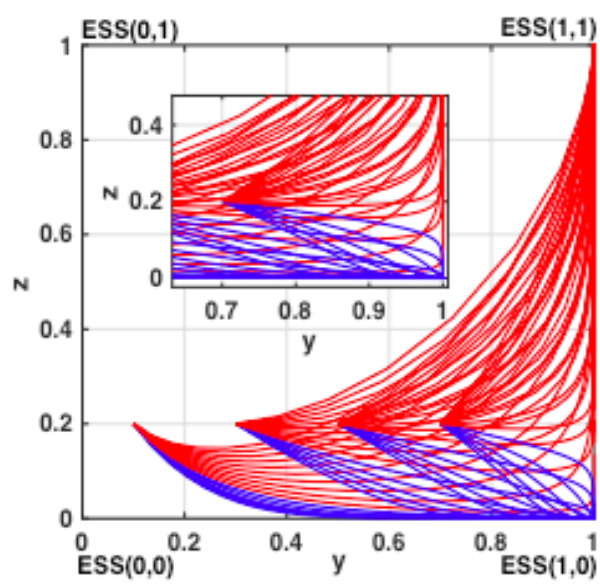

(a) $z_{0}=0.2$

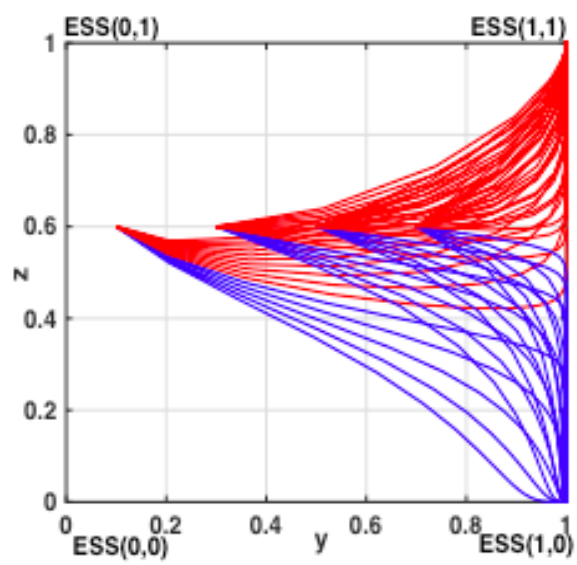

(c) $z_{0}=0.6$

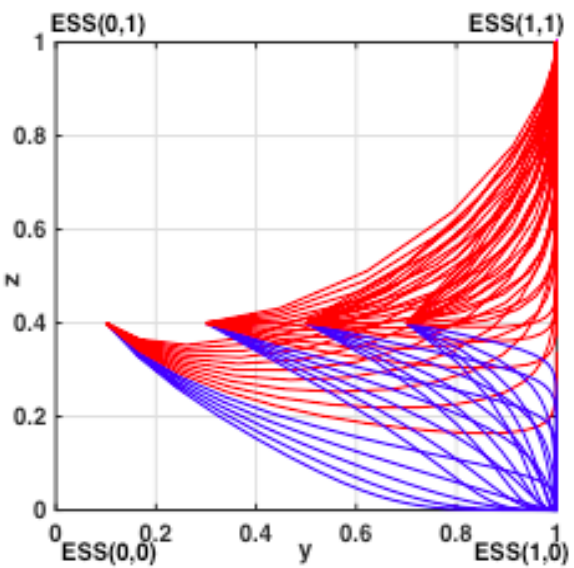

(b) $z_{0}=0.4$

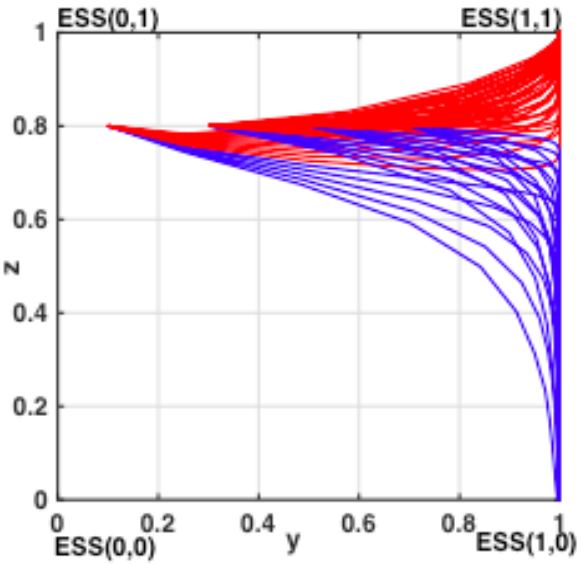

(d) $z_{0}=0.8$

Fig. 6. Dynamic evolutionary diagram of tourism enterprises and tourists with change in $r$

Fig. 6 demonstrates that the dynamic system finally evolves to ESS $(1,0)$, even if tourists have lower green preference owing to the relatively high brand benefit. When tourists' green preference is sufficiently high, the evolutionary path of the dynamic system will finally reach ESS (1,1). Besides, Fig. 6 has similar evolutionary characteristics to that of Fig. 5.

We can conclude from Proposition 4 that when brand benefit of tourism enterprises and green preference of tourists are relatively low, it is impossible to ensure the simultaneous adoption of green operation pattern by tourism enterprises and purchase of green tourism products by the tourists. This case is not uncommon at the early stage 
of green tourism market in some developing countries. Considering China's current situation, wherein environmental protection awareness among the public is not very high, it is ineluctable that central government should create a green incentive mechanism to promote sustainable development of tourism. From the above strategy stability analysis of each stakeholder, we conclude that local governments' supervision can affect the decision of tourism firms. Furthermore, when green preference of tourists satisfies the condition $U+r>p_{1}$, enough green companies can drive tourists to buy green products in the long term. Next, we analyze the ESS between tourism enterprises and tourists under the green incentive mechanism of government.

The aim of local governments implementing green incentive mechanism is to stimulate tourism firms to adopt green innovation and tourists to purchase green products, that is, ESS $(1,1)$. Here, we just identify the condition that can stimulate the dynamic system to evolve into the ideal green tourism pattern ESS $(1,1,1)$. From Eq. (11), we have $\operatorname{det} J_{s}=Q^{2}\left[T x+p_{1}-c+b\right]\left(U+r-p_{1}\right)$ and $\operatorname{tr} J_{s}=-Q(T x-c+$ $b+U+r)$ under ESS $(1,1)$. Accordingly, the local governments can require tourism enterprises to set lower unit price of green products that can ensure $p_{1}<U+r$ by implementing the green incentive mechanism, which can guarantee $T x+p_{1}-c+$ $b>0$. By substituting $y=1$ and $z=1$ into the Eq. (7), we have $F^{\prime}(x)=$ $(1-2 x)\left(U_{g}-C_{g}-Q T\right)$. To ensure that local governments have the motivation to implement green incentive mechanism, the condition $\left.(1-2 x)\left(U_{g}-C_{g}-Q T\right)\right|_{x=1}<$ 0 , that is, $U_{g}-C_{g}>Q T$ should be satisfied. Consequently, Proposition 5 can be obtained.

Proposition 5. The central government can require local governments to implement green incentive mechanism that $T$ satisfies the condition: $\frac{c-b-p_{1}}{x}<T<\frac{U_{g}-C_{g}}{Q}$ to drive the dynamic system to evolve into the ideal green tourism state, that is, ESS $(1,1,1)$.

Proposition 5 identifies the condition that contributes to green tourism development. Observing expression $\frac{c-b-p_{1}}{x}$, it is found that the lower bound is increasing with the decrease of $x$. The fewer the number of firms adopting green tourism, the higher the green incentive intensity is. This implies that the more local governments implement green supervision, the more conducive the implementation of green incentive mechanism is. Similarly, the upper bound of local governments 
implementing green incentive mechanism is decreasing with market demand. This suggests that central government should take the lead in implementing the green incentive mechanism in areas where tourism scale is relatively small. In order to make sure that local governments implement green incentive mechanism, the central government should offer sufficient green policy support, viz., $U_{g}>\frac{\left(c-b-p_{1}\right) Q}{x}+C_{g}$.

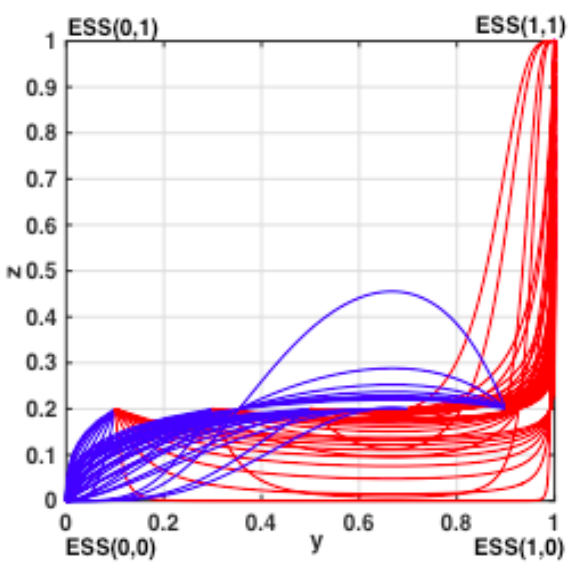

(a) $z_{0}=0.2$

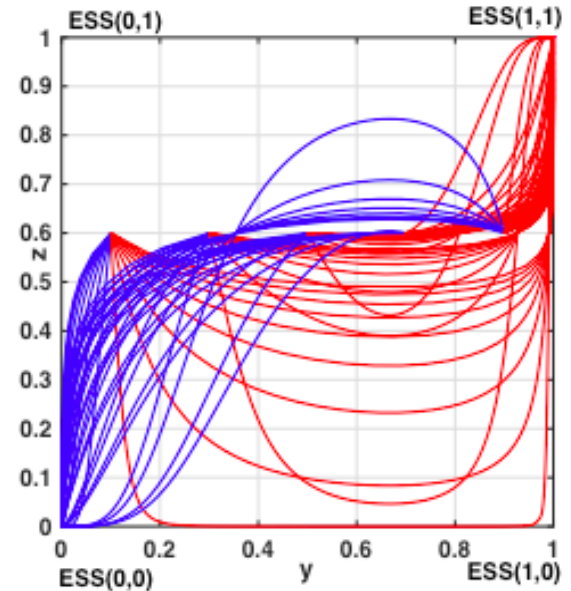

(c) $z_{0}=0.6$

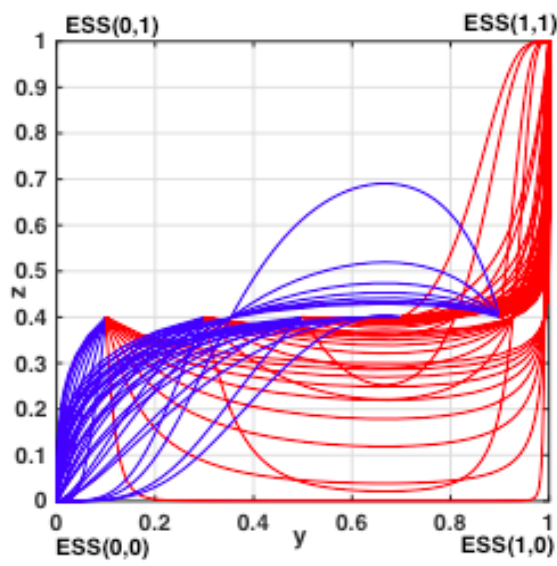

(b) $z_{0}=0.4$

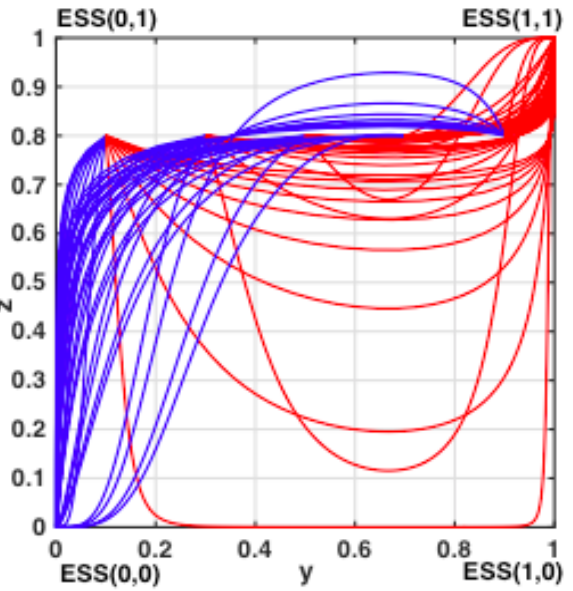

(d) $z_{0}=0.8$

Fig. 7. Dynamic evolutionary diagram of the dynamic system with change in $T$

Fig. 7 examines the role of local governments' green incentive mechanism on the basis of the following parameters value: $U=10, ; b=3 ; r=1, ; p_{1}=10, ; p_{2}=$ 8; $c=18$; and $x_{0}=1$. We make parameter $T$ change over the interval $[0,12]$, in steps of 0.75 . It can be found that when the green incentive intensity is relatively low (blue lines), the local governments cannot drive tourism enterprises and tourists to select green tourism pattern. On the contrary, when the green incentive intensity is high enough (red lines), the green incentive mechanism can motivate traditional tourism to successfully turn toward green development. It is of great importance for local governments to achieve a reasonable incentive intensity, given the thresholds 
mentioned above.

\section{Conclusions and management implications}

In the context of sustainable development, we model a dynamic evolutionary game among local governments, tourism enterprises, and tourists by incorporating green policy support of central government, brand benefit of tourism enterprises, and green preference of tourists. We discuss the strategy evolutionary process of each stakeholder and explore the green incentive mechanism for local governments to promote green tourism development. By numerical experiments, we analyze the impacts of some important parameters on the decision-making of each stakeholder. The main conclusions and managerial insights from evolutionary analyses are as follows.

First, local governments' decision making depends on the simultaneous adoption of strategies by tourism enterprises and tourists. Similarly, tourism enterprises' strategy can be affected by the decisions of both local governments and tourists. It is worth noting that local governments' supervision behavior cannot directly impact the purchasing decision of tourists, but it can indirectly drive the tourists to buy green tourism products by incentivizing tourism firms to sell green products. The research also indicates that some influencing factors, such as social environmental benefit and additional environmental governance cost, cannot affect the strategy stability of the dynamic system even if they exist in reality. Hence, the local governments should focus on enhancing some relatively important factors, such as brand benefit of tourism enterprises and green preference of tourists.

Second, when potential brand benefit is relatively high, tourism enterprises would want to voluntarily adopt a green innovation strategy. As a result, local governments can improve brand benefit to motivate tourism firms to take up the green tourism pattern; the benefit can include giving green tourism enterprises some policy support, and/or granting them green certifications. Therefore, we conclude that when visitors have higher green preference, tourism enterprises would adopt a green innovation strategy, even if local governments do not implement supervision policy. This implies that green preference of tourists can independently guide tour enterprises to implement green tourism innovation through the market mechanism. This is an effective way to strengthen the propaganda of environmental knowledge so as to enhance the tourists' environment awareness. 
Last, it can be concluded that the strategy evolutionary process is influenced by initial states and corresponding stable conditions. The initial states of stakeholders taking part in green activities can affect the short-term decisions of stakeholders but evolutionary stable conditions can influence the decision making of each stakeholder based on the long-term perspective. It is sensible of enterprises and/or local governments to make decisions in the light of the thresholds. Given the green incentive condition $\frac{c-b-p_{1}}{x}<T<\frac{U_{g}-C_{g}}{Q}$, we infer that the dynamic system can evolve into the ideal green tourism state: ESS $(1,1,1)$. It is necessary for all stakeholders to make joint efforts to realize the ideal development path of green tourism. In order to stimulate local governments to perform their duty voluntarily, the central government should enhance green policy support by providing financial subsidy and/or affirming local governments' work. Local governments can promote the green tourism business mode by supporting green technology development, product designing, energy supply, personnel training, and other related works, especially by creating a reasonable green incentive intensity for tourism enterprises. Most importantly, it can be suggested that the government should first implement green incentive mechanism in the areas where tourism scale is relatively small.

We acknowledge a few limitations of our model due to some of its basic assumptions. First, we focused on discussing the game behavior among stakeholders in the vertical dimension; so, horizontal competition in the form of multiple competitors could be analyzed in future studies. The mathematical model in this paper, was influenced by China's tourism industry. Although it has provided some guidelines for similar developing countries, future research could establish a more general model, which could also be applied to developed countries. Moreover, we assumed that the price of tourism product is constant during a certain period. Although it is more complex and challenging, time-varying price could be studied by constructing a profit function. Nevertheless, our research does shed light on the decision making of key stakeholders in sustainable tourism, especially by the government.

\section{Acknowledgments}

We are grateful to the editor and the three anonymous reviewers for their good comments and instructive suggestions, which are all valuable and very helpful for revising and improving our paper. We also would really appreciate Dr. Felix Bello for 
the improvements of our writing. This work was supported by the National Natural Science Foundation of China (Nos. 71771053, 71371003, 71628101 and 41571133) and the Fundamental Research Funds for the Central Universities (No. 2242017K41036).

\section{References}

Bagozzi, R. P., \& Dholakia, U. M. (2006). Antecedents and purchase consequences of customer participation in small group brand communities. International Journal of Research in Marketing, 23(1), 45-61.

Baldacci, R., Hill, A., Hoshino, E. A., \& Lim, A. (2017). Pricing strategies for capacitated ring-star problems based on dynamic programming algorithms. European Journal of Operational Research, 262(3), 879-893.

Barari, S., Agarwal, G., Zhang, W. J., Mahanty, B., \& Tiwari, M. K. (2012). A decision framework for the analysis of green supply chain contracts: An evolutionary game approach. Expert Systems with Applications, 39(3), 2965-2976.

Blanco, E., Lozano, J., \& Rey-Maquieira, J. (2009). A dynamic approach to voluntary environmental contributions in tourism. Ecological Economics, 69(1), 104-114.

Buckley, R. (2012). Sustainable tourism: research and reality. Annals of Tourism Research, 39(2), 528-546.

Budeanu, A., \& Chesworth, N. E. (2007). Sustainable tourist behaviour a discussion of opportunities for change. International Journal of Consumer Studies, 31(5), 499-508.

Chen, L., Wang, Y., Lai, F., \& Feng, F. (2016). An investment analysis for china's sustainable development based on inverse data envelopment analysis. Journal of Cleaner Production, 142(4), 1638-1649.

Chen, M. F., \& Tung, P. J. (2014). Developing an extended theory of planned behavior model to predict consumers' intention to visit green hotels. International Journal of Hospitality Management, 36(1), 221-230.

Chen, T. B., \& Chai, L. T. (2010). Attitude towards the environment and green products: consumers' perspective. Management Science \& Engineering, 4(2), 27-39.

Chen, Y., Yang, S., \& Wang, Z. (2016). Service cooperation and marketing strategies of infomediary and online retailer with eWoM effect. Information Technology \& Management, 17(2), 109-118.

Chu, C. P., \& Chung, K. C. (2016). A framework model for assessing sustainability strategies for 
tourism green supply chain management. Journal of Testing \& Evaluation, 44(3), 1390-1399.

Dunk, R. M., Gillespie, S. A., \& Macleod, D. (2016). Participation and retention in a green tourism certification scheme. Journal of Sustainable Tourism. 24(12), 1585-1603.

Elkington, J. (1998). Cannibals with forks: triple bottom line of 21 st century business john elkington. Environmental Quality Management, 8(1), 37-51.

Encarnação, S., Santos, F. P., Santos, F. C., Blass, V., Pacheco, J. M., \& Portugali, J. (2016). Paradigms shifts and the interplay between state, business and civil sectors. Royal Society Open Science, 3, 160753.

Friedman, D. (1991). Evolutionary games in economics. Econometrica, 59(3), 637-666.

García, D., \& Tugores, M. (2006). Optimal choice of quality in hotel services. Annals of Tourism Research, 33(2), 456-469.

Gössling, S., Peeters, P., Hall, C. M., Ceron, J. P., Dubois, G., Lehmann, L. V., \& Scott, D. (2012). Tourism and water use: supply, demand, and security. An international review. Tourism Management, 33(1), 1-15.

Guo, X., Ling, L., Dong, Y., \& Liang, L. (2013). Cooperation contract in tourism supply chains: The optimal pricing strategy of hotels for cooperative third party strategic websites. Annals of Tourism Research, 41, 20-41.

Han, H. S., \& Haejin, Y. (2015). Hotel customers' environmentally responsible behavioral intention: impact of key constructs on decision in green consumerism. International Journal of Hospitality Management, 45, 22-33.

Hardin, G. (1968). The Tragedy of the Commons. Science, 162 (3859), 1243-1248.

Huang, G. Q., Song, H., \& Zhang, X. (2010). A comparative analysis of quantity and price competitions in tourism supply chain networks for package holidays. The Service Industries Journal, 30(10), 1593-1606.

Huang, J. H., \& Chen, X. Q. (2005). Analyzing the tragedy of common pool tourism resources in china through game theory. Resources Science, 27(5), 180-186.

Huang, Y., Deng, J., Li, J., \& Zhong, Y. (2008). Visitor's attitudes towards China's national park policy, roles and functions and appropriate use. Journal of Sustainable Tourism, 16(1), 63-84

Jinsoo, L., Hsu, L. T., Han, H. S., \& Yunhi, K. (2010). Understanding how consumers view green hotels: how a hotel's green image can influence behavioural intentions. Journal of Sustainable Tourism, 18(7), 901-914.

Kasim, A. (2004). BESR in the hotel sector: a look at tourists' propensity towards environmentally and socially friendly hotel attributes in Pulau Pinang, Malaysia. International Journal of 
Hospitality \& Tourism Administration, 5(2), 61-83.

Kastenholz, E. (2004). 'Management of demand' as a tool in sustainable tourist destination development. Journal of Sustainable Tourism, 12(5), 388-408.

Kim, J-Y., Hlee, S., \& Joun, Y. (2016). Green practices of the hotel industry: analysis through the windows of smart tourism system. International Journal of Information Management, 36(6), 1340-1349.

Li, S. (2011). Regional competition and sustainable development: a game theory model for tourism destinations. European Planning Studies, 19(4), 669-681.

Lin, P. C., \& Huang, Y. H. (2012). The influence factors on choice behavior regarding green products based on the theory of consumption values. Journal of Cleaner Production, 22(1), 1118.

Ling, L., Guo, X., \& Yang, C. (2014). Opening the online marketplace: an examination of hotel pricing and travel agency on-line distribution of rooms. Tourism Management, 45(1), 234-243.

Liu, H., Zhou, G., Wennersten, R., \& Frostell, B. (2014). Analysis of sustainable urban development approaches in china. Habitat International, 41(1), 24-32.

Lu, J., \& Nepal, S. K. (2009). Sustainable tourism research: an analysis of papers published in the Journal of Sustainable Tourism. Journal of Sustainable Tourism, 17(1), 5-16.

Miller, G., Rathouse, K., Scarles, C., Holmes, K., \& Tribe, J. (2010). Public understanding of sustainable tourism. Annals of Tourism Research, 37(3), 627-645.

Panda, S., Modak, N. M., Basu, M., \& Goyal, S. K. (2015). Channel coordination and profit distribution in a social responsible three-layer supply chain. International Journal of Production Economics, 168, 224-233.

Peattie, K. (2010). Green consumption: behavior and norms. Annual Review of Environment \& Resources, 35(1), 195-228.

Roberts, S., \& Tribe, J. (2008). Sustainability indicators for small tourism enterprises-an exploratory perspective. Journal of Sustainable Tourism, 16(5), 575-594.

Saarinen, J. (2014). Understanding and governing sustainable tourism mobility: psychological and behavioural approaches. Anatolia An International Journal of Tourism \& Hospitality Research, 26(1), 119-121.

Santos, F. P., Encarnação, S., Santos, F. C., Portugali, J., \& Pacheco, J. M. (2016). An evolutionary game theoretic approach to multi-sector coordination and self-organization. Entropy, 18(4), 152.

Serra-Cantallops, A., Peña-Miranda, D. D., Ramón-Cardona, J., \& Martorell-Cunill, O. (2017). Progress in research on CSR and the hotel industry (2006-2015). Cornell Hospitality Quarterly, 
59(1), 15-38.

Simões, F.D. (2016). Consumer behavior and sustainable development in china: the role of behavioral sciences in environmental policymaking. Sustainability, 8(9), 897.

Smith, J. M., \& Price, G. R. (1973). The logic of animal conflict. Nature, 246(5427), 15-18.

Su, L., \& Swanson, S. R. (2017). The effect of destination social responsibility on tourist environmentally responsible behavior: compared analysis of first-time and repeat tourists. Tourism Management, 60, 308-321.

Swarbrooke, J. (1999). Sustainable tourism management. Annals of Tourism Research, 28(2), 523525 .

Tang, C. C., Zhong, L. S., \& Cheng, S. K. (2011). Study on the connotations and sustainable development strategies on low-carbon tourism in China. Economic Geography, 31(5), 862-867.

Taylor, P. D., \& Jonker, L. B. (1978). Evolutionary stable strategies and game dynamics. Mathematical Biosciences, 40, 145-156.

Vermeir, I., \& Verbeke, W. (2006). Sustainable food consumption: exploring the consumer "attitudebehavioral intention" gap. Journal of Agricultural and Environmental Ethics, 19(2), 169-194.

Weibull, J.W. (1997). Evolutionary Game Theory. MIT Press: Cambridge, MA.

Wie, B. W. (2005). A dynamic game model of strategic capacity investment in the cruise line industry. Tourism Management, 26(2), 203-217.

Xu, F., \& Fox, D. (2014). Modelling attitudes to nature, tourism and sustainable development in national parks: A survey of visitors in China and the UK. Tourism Management, 45(1), 142158.

Yan, H. L. (2013). Green book of china's tourism 2011: China's tourism development analysis and forecast. Journal of Tourism and Cultural Change, 11(1-2), 140-143.

Yang, L., Ji, J. N., \& Chen, K. B. (2016). Game models on optimal strategies in a tourism dualchannel supply chain. Discrete Dynamics in Nature and Society, 1-15.

Yang, Z. Z., Hong, S., Dan, Y., Cai, Y. C., \& Ren, X. Y. (2015). Analysis of core stakeholder behaviour in the tourism community using economic game theory. Tourism Economics, 21(6), 1169-1187.

Zhang, D., \& Weatherford, L. (2017). Dynamic pricing for network revenue management: a new approach and application in the hotel industry. Informs Journal on Computing, 29(1), 18-35.

Zhang, Q., \& Crooks, R. (2012). Toward an environmentally sustainable future: country environmental analysis of the People's Republic of China. Asian Development Bank.

Zhao, L. M., Chen, Z. Z., \& Liu, J. Y. (2015). Evolutionary game theory between local government 
and tourism enterprises in the context of a low-carbon economy. Tourism Tribune, 30(1), 7282.

Zhu, W., \& He, Y. (2016). Green product design in supply chains under competition. European Journal of Operational Research, 258(1), 165-180.

Zyl, C. V. (2012). Tourism marketing: a game theory tool for application in arts festivals. Tourism Economics, 18(18), 43-57. 